\title{
PENENTUAN OPTIMASI PARAMETER PERMESINAN TERHADAP KEKASARAN BAJA ST 42 HASIL PROSES BUBUT MENGGUNAKAN METODE TAGUCHI
}

\author{
Alfiansyah Riady ${ }^{1)}$, Mastiadi Tamjidillah ${ }^{2)}$ \\ ${ }^{1,2}$ Program Studi Teknik Mesin, \\ Fakultas Teknik Universitas Lambung Mangkurat \\ JL. Ahmad Yani Km.36 Banjarbaru, Kalimantan Selatan,70714 \\ Telp. 0511-4772646, Fax 0511-4772646 \\ E-mail : aliriady24@gmail.com
}

\begin{abstract}
Abstrak Penelitian ini bertujuan Meningkatkan Produktivitas Pembubutan Menggunakan Metode Taguchi. Dalam perusahaan industri lama pengerjaan dari suatu produk sangat mempengaruhi ongkos kerja dan tingkat produktivitas pemesinan, sehingga diperlukan suatu metode agar dapat mengoptimalkan tingkat produktivitas. Metode Taguchi dapat digunakan untuk melakukan optimasi untuk mendapatkan tingkat produktivitas pemesinan terbaik. Penelitian ini menggunakan material baja ST 42 dengan proses pemesinan bubut konvensional. Dapat diketahui dalam penelitian ini untuk mendapatkan kekasaran yang paling baik atau optimum parameter pembubutan yang digunakan yaitu pada putaran spindel $490 \mathrm{rpm}$, gerak makan $0.11 \mathrm{~mm} /$ put, kedalaman makan $0.2 \mathrm{~mm}$. faktor yang paling berpengaruh dalam penelitian ini iadalah putaran spindel $41.6 \%$, gerak makan $46.3 \%$ sedangkan kedalaman makan kurang berpengaruh yaitu sebesar $5.4 \%$.
\end{abstract}

Kata kunci; Optimasi, Pembubutan, Bubut muka, Kekasaran, Metode Taguchi

Abstract This study aims to increase the Productivity of Rolling Using Taguchi Method. In the old industrial company the work of a product greatly affects the work cost and the level of machinary productivity, so it needs a method in order to optimize the level of productivity. The Taguchi method can be used to optimize to get the best machining productivity level. This research uses ST 42 steel material with conventional lathe machining process. It is known in this study to obtain the best roughness or optimum parameters used in the spindle rotation is $490 \mathrm{rpm}$, feeding motion $0.11 \mathrm{~mm} / \mathrm{rev}, 0.2 \mathrm{~mm}$ feeding depth. the most influential factor in this research is spindle rotation $41.6 \%$, feeding $46.3 \%$ while the eating depth is less influential that is equal to $5.4 \%$.

Keywords; Optimization, Lathe, Lathe face, Roughness, Taguchi Method

\section{PENDAHULUAN}

Pada saat ini, telah terjadi tuntutan yang semakin tinggi terhadap kualitas hasil proses pemotongan logam di Indonesia. Hal ini terkait dengan meningkatnya daya saing dan permintaan akan produk yang berkualitas di pasar. Untuk menghasilkan produk yang berkualitas, industri manufaktur harus mengendalikan proses manufakturnya. Olehi karena itu, industri manufaktur melakukan proses perbaikan yang dari berkesinambungan terhadap 
pengendalian kualitas dari proses-proses pemotongan logam. Peningkatan efisiensi proses signifikan yang dapat diperoleh dengan mengoptimalkan parameter proses yang teridentifikasi. Secara umum parameter-parameter pada proses pemotongan logam adalah putaran spindel (n), gerak makan (f) dan kedalaman potong (a).

Penentuan kombinasi parameter yang tepat untuk produk-produk pemesinan yang memiliki beberapa performansi karakteristik cukup sulit dilakukan karena kompleksitas yang dimiliki dan harus mengandalkan sejumlah besar rangkaian percobaan. Pada proses pemesinan, penentuan seting parameter proses yang tepat untuk mencapai respon yang optimum sangat penting dilakukan secara efektif.

Proses bubut (turning) dalam industri manufaktur merupakan salah satu proses yang digunakan dalam pemotongan logam. Lebih kurang $80 \%$ dari keseluruhan kegiatan yang ada pada operasi proses pemotongan logam menggunakan proses bubut operasi pemotongan yang dapat dilakukan menggunakan proses bubut diantaranya straight turning, taper turning, proflling, turning and ectearnal grooving, cutting with a form tool, facing, face igrooving, boring and internal grooving, drilling, cutting off, threading serta knurling. Perkembangan cuttingi tool iseperti ipahat ibubut jenisi carbide, CBN, keramik, dan inserts tool sudah semakin maju. Meskipun demikian, jenis pahat konvensional salah satunya jeniis pahat HSS (high speed steel) masih tetap digunakan (Rochim, 1993) terutama di bengkel produksi yang bersekala kecil sampai menengah. Hal ini dimungkinkan karena pahat jenis HSS bersifat liat, mudah diasah, harga lebih rendah, mudah didapat serta memungkinkan aplikasi pengerjaan dengan pemotongan (speed and feed) yang lebih rendah.
Penggunaan baja telah mengalami peningkatan yang cukup pesat di industri material manufaktur dimana sebagian ditentukan oleh nilai ekonomisnya. Baja ST 42 merupakan salah satu jenis baja karbon rendah yang memiliki sifat mudah di tempa dan mudah di proses permesinan. Pahat bubut HSS banyak digunakan untuk melakukan proses permesinan baja ST 42 dalam pembuatan roda gigi, poros dan baut. Pada proses penyelesaian pekerjaan, selain dimensi produk jadi, kekasaran permukaani (surface roughness) merupakan salah satu karakteristik kualitas yang kritis (Critical to Quality Charactersistcs/CTQ) yang penting untuk menunjukkan kualitas pengerjaan. Secara khusus kekasaran permukaan memegang peranan penting pada kualitas produk dan merupakan salah satu parameter yang penting untuk mengevaluasi dari hasil proses keakurasian permesinan. Selain kekasaran permukaan, pengukuran keausan pahat (tool wear) juga diperlukan, karena dalam proses permesinan harga produksi banyak dipengaruhi oleh penggunaan pahat. Semakin pendek umur pahat, semakin cepat pula pahat harus diganti, sehingga biaya yang dikeluarkan juga semakin besar. Banyak penelitian yang menunjukkan kecepatan potong kedalaman potong, dan gerak makan memiliki pengaruh terhadap keausan pahat dan kekasaran permukaan benda kerja. Metode Taguchi digunakan untuk menentukan rancangan eksperimen, dengan parameter proses yang meliputi kecepaatan potong, kedalaman potong dan gerak makan, masing -masing 3 level pada proses bubut material St. 37 dengan pahat Widia CNGA120408T. Hasil penelitian menunjukkan parameter yang berpengaruh pada respon secara optimal adalah gerak makan pada level 1 atau $0,112 \mathrm{~mm} / \mathrm{rev}$ 
dan kecepatan potong pada level 3 atau $110 \mathrm{~m} / \mathrm{min}$.

\section{METODE PENELITIAN}

Metode penelitian yang dilakukan dengan metode Taguchi. Metode ini dicetuskan olehi Dr. Henichi Taguchi pada tahun 1949 saat mendapatkan tugas untuk memperbaiki sistem telekomunikasi Jepang. Metode Taguchi merupakan suatu metodelogi baru dalam bidang teknik yang bertujuan untuk memperbaiki kualitas produk dan proses dalam waktu yang bersamaan menekan biaya dan sumber seminimal mungkin. Sasaran metode taguchi adalah menjadikan produk kokoh (robust) atau tidak sensitif terhadap berbagai faktor gangguan (noise), karena itu sering disebut sebagai desain kokoh (robust design).

Pada percobaan ini menggunakan 3 buah faktor dan 3 level untuk setiap faktornya, sebagaimana terlihat pada Tabel 1 .

Tabel 1. Variabel bebas

\begin{tabular}{|c|l|ccc|}
\hline \multirow{2}{*}{ Kode } & \multicolumn{1}{|c|}{ faktor } & \multicolumn{3}{|c|}{ Level } \\
\cline { 3 - 5 } & & 1 & 2 & 3 \\
\hline A & Kecepatan spindel (rpm) & 330 & 490 & 650 \\
B & Gerak makan (mm/put) & 0,11 & 0,33 & 0,52 \\
C & Kedalaman Pemakanan (mm) & 0,200 & 0,400 & 0,600 \\
\hline
\end{tabular}

Setelah menentukan level dari tiap faktor, masukan nilainya ke aplikasi Minitab 18 sesuai dengan Tabel 1 sehinggai diperoleh rancangan percobaan sesuai dengan Tabel 2 .

Tabel 2. Orthogonal array L9 dengan faktor dan level

\begin{tabular}{|l|l|l|l|}
\hline \multirow{2}{*}{$\begin{array}{l}\text { No. } \\
\text { spesimen }\end{array}$} & \multicolumn{3}{|l|}{ Parameter Kendali } \\
\cline { 2 - 4 } & A & B & C \\
\hline 1 & 330 & 0,11 & 0,2 \\
\hline 2 & 330 & 0,33 & 0,4 \\
\hline 3 & 330 & 0,52 & 0,6 \\
\hline 4 & 490 & 0,11 & 0,4 \\
\hline 5 & 490 & 0,33 & 0,6 \\
\hline 6 & 490 & 0,52 & 0,2 \\
\hline 7 & 650 & 0,11 & 0,6 \\
\hline 8 & 650 & 0,33 & 0,2 \\
\hline 9 & 650 & 0,52 & 0,4 \\
\hline
\end{tabular}

Diagram alir penelitian dapat dilihat pada Gambar 1.

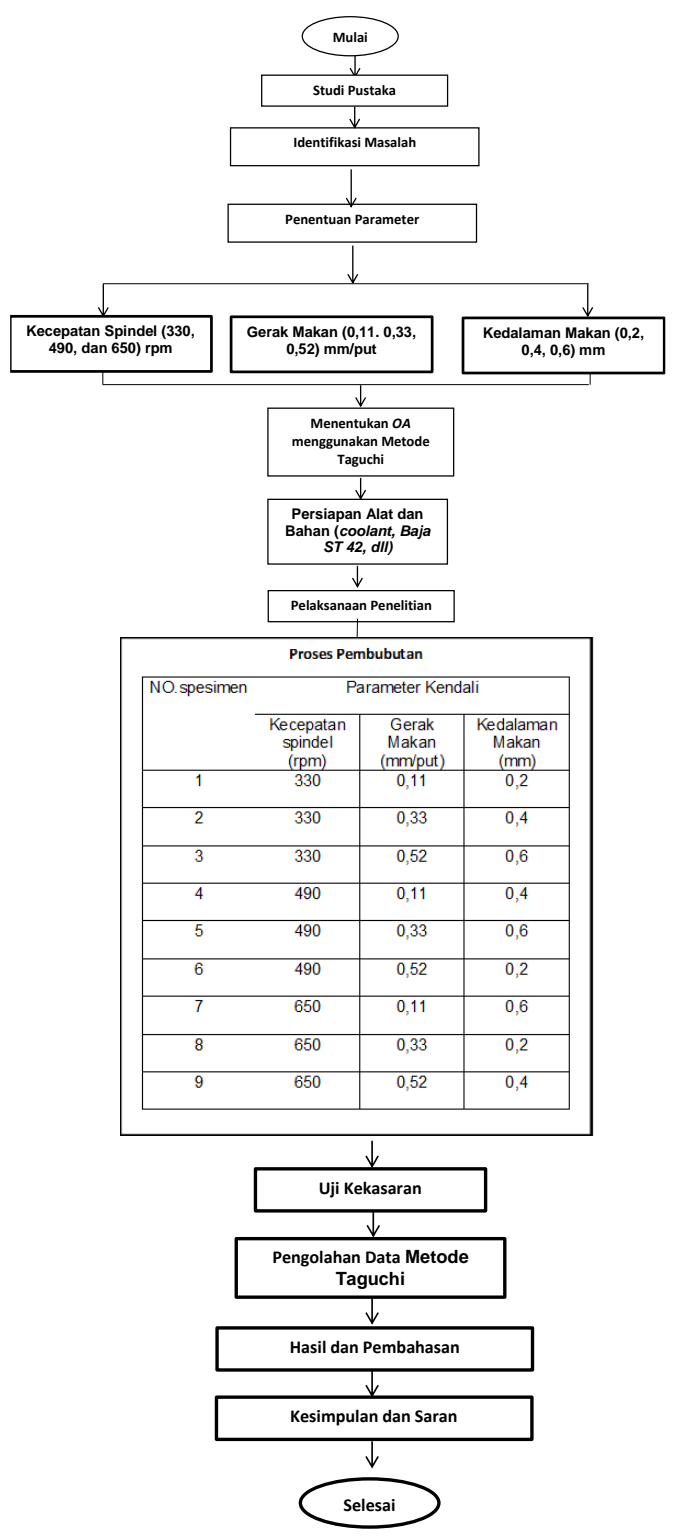

Gambar 1. Diagram alir penelitian 


\section{HASIL DAN PEMBAHASAN}

Data hasil pengukuran kekasaran bisa dilihat pada tabel 3 .

Tabel 3. Data hasil pengujian kekasaran

\begin{tabular}{|c|c|c|c|c|c|}
\hline $\begin{array}{l}\text { No. } \\
\text { Spe } \\
\text { sim } \\
\text { en }\end{array}$ & $\begin{array}{l}\text { Replik } \\
\text { asi }\end{array}$ & \multicolumn{3}{|c|}{$\begin{array}{l}\text { NILAI KEKASARAN } \\
\text { Ra } \\
\text { TITIK } 1 \text { TITIK } 2 \text { TITIK } 3\end{array}$} & $\begin{array}{l}\text { Rata - } \\
\text { rata Ra }\end{array}$ \\
\hline \multirow[t]{3}{*}{1} & $1_{1}$ & 4.287 & 3.912 & 3.152 & \multirow[t]{3}{*}{$\begin{array}{c}4.19911 \\
111\end{array}$} \\
\hline & $1_{2}$ & 3.852 & 4.041 & 4.208 & \\
\hline & $1_{3}$ & 4.852 & 4.985 & 4.503 & \\
\hline \multirow[t]{3}{*}{2} & 21 & 4.965 & 5.54 & 7.54 & \multirow[t]{3}{*}{$\begin{array}{c}6.06622 \\
222\end{array}$} \\
\hline & 22 & 5.111 & 5.718 & 6.663 & \\
\hline & 23 & 5.024 & 7.851 & 6.184 & \\
\hline \multirow[t]{3}{*}{3} & $3_{1}$ & 7.954 & 7.372 & 8.466 & \multirow[t]{3}{*}{$\begin{array}{c}9.29488 \\
889\end{array}$} \\
\hline & $3_{2}$ & 8.227 & 7.843 & 8.331 & \\
\hline & $3_{3}$ & $\begin{array}{c}12.67 \\
4\end{array}$ & $\begin{array}{c}12.14 \\
1\end{array}$ & $\begin{array}{c}10.64 \\
6\end{array}$ & \\
\hline \multirow[t]{3}{*}{4} & $4_{1}$ & 3.466 & 4.494 & 4.506 & \multirow[t]{3}{*}{$\begin{array}{c}4.20744 \\
444\end{array}$} \\
\hline & $4_{2}$ & 4.651 & 5.063 & 3.796 & \\
\hline & 43 & 4.414 & 3.873 & 3.604 & \\
\hline \multirow[t]{3}{*}{5} & $5_{1}$ & 5.425 & 3.319 & 5.105 & \multirow[t]{3}{*}{5.639} \\
\hline & 52 & 5.527 & 6.103 & 4.996 & \\
\hline & $5_{3}$ & 6.043 & 7.898 & 6.335 & \\
\hline \multirow[t]{3}{*}{6} & 61 & $\begin{array}{c}10.47 \\
8\end{array}$ & 7.994 & 9.963 & \multirow[t]{3}{*}{$\begin{array}{c}9.79788 \\
889\end{array}$} \\
\hline & 62 & $\begin{array}{c}11.13 \\
1\end{array}$ & 7.994 & 9.963 & \\
\hline & 63 & 9.442 & $\begin{array}{c}10.84 \\
8\end{array}$ & $\begin{array}{c}10.36 \\
8\end{array}$ & \\
\hline \multirow[t]{3}{*}{7} & $7_{1}$ & 13.26 & 10.24 & $\begin{array}{c}10.50 \\
6\end{array}$ & \multirow[t]{3}{*}{$\begin{array}{c}11.2228 \\
889\end{array}$} \\
\hline & 72 & 9.494 & 8.82 & 6.671 & \\
\hline & $7_{3}$ & $\begin{array}{c}14.77 \\
1\end{array}$ & 13.25 & $\begin{array}{c}13.99 \\
4\end{array}$ & \\
\hline \multirow[t]{3}{*}{8} & 81 & 6.751 & 5.947 & 7.738 & \multirow[t]{3}{*}{$\begin{array}{c}7.27055 \\
556\end{array}$} \\
\hline & $8_{2}$ & 6.719 & 6.381 & 6.568 & \\
\hline & $8_{3}$ & 10.15 & 7.744 & 7.437 & \\
\hline \multirow[t]{3}{*}{9} & $9_{1}$ & $\begin{array}{c}11.89 \\
7\end{array}$ & 13.72 & 12.6 & \multirow[t]{3}{*}{$\begin{array}{c}17.7503 \\
333\end{array}$} \\
\hline & $9_{2}$ & $\begin{array}{c}24.51 \\
7\end{array}$ & $\begin{array}{c}23.63 \\
3\end{array}$ & $\begin{array}{c}23.43 \\
9\end{array}$ & \\
\hline & $9_{3}$ & $\begin{array}{c}16.3 \\
16\end{array}$ & $\begin{array}{c}17.1 \\
16\end{array}$ & $\begin{array}{c}16.5 \\
15\end{array}$ & \\
\hline
\end{tabular}

\section{Perhitungan rasio $\mathrm{S} / \mathrm{N}$}

Rasio S/N (Signal to Noise) digunakan untuk memilih kombinasi level pada tiap faktor yang memiliki kontribusi pada pengurangan variasi suatu respon. Rasio $S / N$ merupakan suatu rancangani untuk melakukan transformasi pengulangan data kedalam suatu nilai yang merupakan ukuran variasi yang timbul. Nilai $S / N$ ratio dapat dilihat pada Tabel 4.

Tabel 4. Nilai $S / N$ ratio

\begin{tabular}{|c|c|c|c|c|}
\hline N0 & $\mathrm{A}$ & B & $\mathrm{C}$ & SNRA1 \\
\hline 1 & 330 & 0,11 & 0,2 & $\begin{array}{l}- \\
12.4631\end{array}$ \\
\hline 2 & 330 & 0,33 & 0,4 & $\begin{array}{l}- \\
15.6584\end{array}$ \\
\hline 3 & 330 & 0,52 & 0,6 & $\begin{array}{l}- \\
19.3649\end{array}$ \\
\hline 4 & 490 & 0,11 & 0,4 & $\begin{array}{l}- \\
12.4804\end{array}$ \\
\hline 5 & 490 & 0,33 & 0,6 & $\begin{array}{l}- \\
15.0240\end{array}$ \\
\hline 6 & 490 & 0,52 & 0,2 & $\begin{array}{l}- \\
19.8227\end{array}$ \\
\hline 7 & 650 & 0,11 & 0,6 & $\begin{array}{l}- \\
21.0021\end{array}$ \\
\hline 8 & 650 & 0,33 & 0,2 & $\begin{array}{l}- \\
17.2314\end{array}$ \\
\hline 9 & 650 & 0,52 & 0,4 & $\begin{array}{l}- \\
24.9841\end{array}$ \\
\hline
\end{tabular}

\section{Respon S/N Ratio}

Dari perhitungan signal to noise ratio diatas dapat diketahui nilai dari masingmasing faktor (parameter) dan level yang paling berpengaruh, dengan melakukan perhitungan nilai rata-rata pengujian kekasaran untuk setiap faktor terhadap rata-rata kekasaran permukaan dilakukan pengolahan data respon kekasaran permukaan yangi diperoleh langsung dari pengujian kekasaran permukaan. Untuki responi kekasaran permukaan, pengaruh levelnya terlihat pada Tabel 5. 
Tabel 5. S/N Ratio untuk respon nilai kekasaran smaller the better

\begin{tabular}{|l|l|l|l|}
\hline Level & A & B & C \\
\hline 1 & -15.83 & -15.32 & -16.51 \\
\hline 2 & -15.78 & -15.97 & -17.71 \\
\hline 3 & -21.07 & -21.39 & -18.46 \\
\hline Delta & 5.30 & 6.08 & 1.96 \\
\hline Rank & 2 & 1 & 3 \\
\hline
\end{tabular}

Dari tabel di atas, dapat diubah ke dalam bentuk grafik seperti Gambar 2.

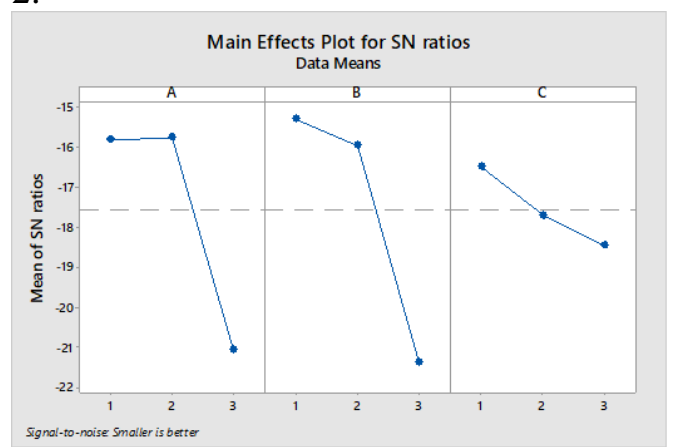

Gambar 2. Grafik respon S/N ratio kekasaran permukaan

\section{Perhitungan Analisa Variasi (ANOVA)} Analisa variasi (ANOVA) digunakan untuk mengetahui ada tidaknya pengaruh faktor terhadap kekasaran baja ST 42 hasil proses bubut. Analisis varian dalam penelitian ini dihitung menggunakan software minitab 18. Hasil ANOVA kekasaran permukaan bisa dilihat pada Tabel 4.

Tabel 4. ANOVA

\begin{tabular}{|c|c|c|}
\hline $\begin{array}{l}\text { Source } \\
\text { Value } \\
\%\end{array}$ & $\begin{array}{l}\text { DF Adj SS } \\
\text { P-Value }\end{array}$ & $\begin{array}{l}\text { Adj MSF- } \\
\text { p-contribution }\end{array}$ \\
\hline A & $\begin{array}{ll}2 & 61.543 \\
0.135 & 41.6 \\
\end{array}$ & $30.772 \quad 6.40$ \\
\hline B & $\begin{array}{ll}2 & 68.442 \\
0.123 & 46.3\end{array}$ & 34.2217 .12 \\
\hline $\mathrm{C}$ & $\begin{array}{ll}2 & 8.116 \\
0.542 & 5.4 \\
\end{array}$ & $4.058 \quad 0.84$ \\
\hline Error & 9.619 & 4.810 \\
\hline Total & 147.720 & \\
\hline
\end{tabular}

\section{Pembahasan}

Pengujian kekasaran permukaan menghasilkan data berupa angka (nilai) kekasaran permukaan rata-rata $(\mathrm{Ra})$. Data tersebut diperoleh dari pengukuran dengan menggunakan alat ukur kekasaran (surface roughness tester ).

Pengukuran tersebut dilakukan setelah material di bubut dengan tiga variasi yaitu kecepatan spindle (A) yaitu $330 \mathrm{rpm}, 490 \mathrm{rpm}, 650 \mathrm{rpm}$; tiga variasi gerak makan (B) yaitu 0,11 $\mathrm{mm} /$ put, $0,33 \mathrm{~mm} /$ put, $0,52 \mathrm{~mm} /$ put; tiga variasi kedalaman makan (C) yaitu 0,2 $\mathrm{mm}, 0,4 \mathrm{~mm}, 0,6 \mathrm{~mm}$. hasil pengukuran ini dapat dilihat pada tabel . Berikut adalah hasil dari pengolahan data diatas sebagai berikut.

Berdasarkan respon kekasaran permukaan yang paling berpengaruh atau rank 1 yaitu A (gerak makan), rank 2 yaitu B (kecepatan spindel) dan rank 3 yaitu $C$ (kedalaman makan).

Berdasarkan nilai $\mathrm{S} / \mathrm{N}$ ratio terhadap hasil kekasaran yang paling tinggi adalah kombinasi parameter kecepatan spindel pada level 1 yaitu $330 \mathrm{rpm}$, gerak makan pada level 1 yaitu $0,11 \mathrm{~mm} /$ put, dan kedalaman makan pada level 1 yaitu 0,2 mm sebesar - $12.4631 \mathrm{db}$. Dikatakan bahwa semakin besar nilai $\mathrm{S} / \mathrm{N}$ ratio maka kualitas jalur atau kombinasi eksperimen tersebut tinggi. Artinya, makin besar pula kemungkinan level-level kombinasi parameter itu dipakai untuk menentukan nilai kekasaran terbaik.

Berdasarkan tabel dan grafik pengaruh respon kekasaran permukaan menunjukkan kecepatan spindel menempati rank 2, gerak makan rank 1 dan kedalaman makan rank 3. Dan dapat juga diketahui kondisi optimumnya yaitu pada kecepatan putaran spindel $490 \mathrm{rpm}$, gerak makan $0,11 \mathrm{~mm} /$ put, kedalaman makan 0,2 $\mathrm{mm}$. 
Berdasarkan ANOVA keputusan uji yang dapat diambil sebagai berikut a. $F_{\mathrm{uji}}=6,40$ dan $\mathrm{F}_{\text {tabel }}=4,46$ sehingga $\mathrm{F}_{\mathrm{uji}}$ $>\mathrm{F}_{\text {tabel. }}$ Jadi, kecepatan spindel cukup berpengaruh terhadap tingkat kekasaran. Hipotesis pertama dapat diterima. Dengan kontribusi pengaruh $41,6 \%$

b. $F_{u j i}=7,12$ dan $F_{\text {tabel }}=4,46$ sehingga $F_{u j i}$ $>\mathrm{F}_{\text {tabel. }}$ Jadi, gerak makan cukup berpengaruh terhadap tingkat kekasaran. Hipotesis kedua dapat diterima. Dengan kontribusi pengaruh $46,3 \%$

c. $F_{u j i}=0,08$ dan $F_{\text {tabel }}=4,46$ sehingga $F_{u j i}<$ $\mathrm{F}_{\text {tabel. }}$ Jadi, kedalaman makan kurang berpengaruh berpengaruh terhadap tingkat kekasaran. Hipotesis ketiga ditolak. Dengan kontribusi pengaruh 5,4\%.

Berdasarkan hasil hipotesis diatas dapat diketahui bahwa pengaruh kekasaran permukaan baja ST 42 hasil proses bubut paling berpengaruh adalah parameter gerak makan dan kecepatan spindel, bahwa $\mathrm{F}_{\mathrm{uji}}>\mathrm{Ft}_{\mathrm{abel}}$. Sedangkan kedalaman makan kurang berpengaruh terhadap kekasaran karena $\mathrm{F}_{\mathrm{uji}}<\mathrm{Ft}_{\mathrm{abel}}$.

Menurut Pragnesh (2012) laju pemakanan adalah hal yang sangat berpengaruh terhadap kekasaran permukaan dibandingkan kedalaman potong dan kecepatan potong. Sudhansu (2013) mengatakan bahwa kecepatan potong saja yang merupakan hal yang sangat berpengaruh terhadap kekasaran permukaan, sedangkan kedalaman potong tidak berpengaruh terhadap kekasaran permukaan. Hal ini dibuktikan dengan menggunakan Design of Experiment (DOE). Demikian pula dengan Natarajan (2011) yang mengatakan bahwa pada kecepatan $2500 \mathrm{rpm}$ dan $3250 \mathrm{rpm}$ angka kekasaran permukaan semakin menurun seiring dengan kecepatan pemotongan.

\section{KESIMPULAN}

Kesimpulan yang dapat diambil dalam penelitian ini adalah sebagai berikut:
1. Parameter yang cukup berpengaruh terhadap kekasaran permukaan adalah kecepatan spindel dengan kontribusi pengaruh 41,6\% dan gerak makan dengan kontribusi pengaruh sebesar 46,3\%. Sedangkan kedalaman makan kurang berpengaruh terhadap kekasaran permukaan dengan kontribusi pengaruh sebesar $5,4 \%$.

2. Rancangan komposisi optimum Metode Taguchi untuk kekasaran permukaan yang terbaik adalah kecepatan spindel pada kecepatan 490 rpm, gerak makan pada kecepatan $0,11 \mathrm{~mm} /$ put dan kedalaman makan pada kedalaman $0,2 \mathrm{~mm}$.

\section{DAFTAR PUSTAKA}

Abda'u, Faizal. 2014. Pengaruh Jenis Pahat, Jenis Pendingin, dan Kedalaman Pemakanan Terhadap Kerataan Dan Kekasaran Permukaan Baja ST 42 Pada Proses Bubut Rata Muka. Surabaya. JTM. Volume 03 Nomor 01 Tahun 2014, 23 - 32.

Anggit, Daniar A. pengaruh jenis pahat dan cairan pendingin serta kedalaman pemakanan terhadap tingkat kekasaran dan kekerasan permukaan baja ST 60. Surabaya.JTM. Volume 01 Nomor 03 Tahun 2013, 83-90

Lesmono, Indra dan Yunus. 2013. Pengaruh Jenis Pahat, Kecepatan Spindle, dan Kedalaman Pemakanan Terhadap Kekasaran dan Kekerasan Permukaan Baja ST. 42 pada Proses Bubut Konvensional. Jurnal: JTM. Surabaya: Universitas Negeri Surabaya. Vol: 1. Nomor: 3.

Natarajan, dkk. 2011. Investigation of Cutting Parameters of Surface Roughness for a Non-Fereous Material Using Artificial Neural Network in CNC Turning. (Online), 
(http://www.academicjournals.or g/jmer) diakses 15 Juli 2014.

Nugroho, T.U., Saputro, Herman. Dan

Estriyanto, Yuyun. 2012.

Pengaruh Kecepatan Pemakanan

Dan Waktu Pemberian Pendingin Terhadap Tingkat Keausan Cutter End Mill Hss Hasil Pemesinan Cnc Milling Pada Baja St 40. Skripsi : Fakultas Keguruan dan Ilmu Keguruan Universitas Sebelas Maret, Surakarta, Indonesia.

Patel, Pragnesh. R. 2012. Effect of Machining Parameters on Roughness and Power Consumption for 6063 al Alloy TiC Composites (MMCs). (Online), (www.ijera.com) diakses 15 Juli 2014

Rochim T. 1993. Proses Permesinan. Higher Education Development Support Project. Jakarta.

Sidi, Pranowo. 2014. Skripsi. Optimasi nilai kekasaran permukaan pada proses bubut cnc dengan metode taguchi. Surabaya. Politeknik Perkapalan Negeri Surabaya (PPNS).

Sudhansu, dkk. 2013. Effect of Machining on Surface Roughness in Machining of Hardened AISI 4340 Steel Using Coated Carbides Inserts. (http://www.issr-

journals.org/ijias/) diakses 15 Juli 2014.

Suseno, agung. 2016. Skripsi. Analisis Variasi Metode Pendinginan Milling CNC Tipe VMC-L540 Pada Kekasaran Permukaan S45C dengan Metode Taguchi. Universitas Jember.

Wang M.Y., dan Chang H.Y. 2004. "Experimental study of surface roughness in slot end milling AL2014-T6", International Journal of Machine Tools \&
Manufacture, Vol. 44, No. 1, pp. 51-57.

Widarto. 2008. Teknik Permesinan Jilid 1. Jakarta: Direktorat Pembinaan Sekolah Menengah Kejuruan.

Widarto. 2008. Teknik Permesinan Jilid 2. Jakarta: Direktorat Pembinaan Sekolah Menengah Kejuruan. 